\title{
Effect of Magnesium Sulphate on Self-Compacting Concrete Containing Supplementary Cementitious Materials
}

\author{
Aiad Hassan, ${ }^{1}$ Hilmi Bin Mahmud, ${ }^{1}$ Mohd. Zamin Jumaat, ${ }^{1}$ \\ Belal ALsubari, ${ }^{1}$ and Aziz Abdulla ${ }^{2}$ \\ ${ }^{1}$ Department of Civil Engineering, University of Malaya Malaysia, Kuala Lumpur, Malaysia \\ ${ }^{2}$ Departments of Civil Engineering, Tikrit University, Tikrit, Iraq \\ Correspondence should be addressed to Aiad Hassan; ayaadhamed@yahoo.com
}

Received 15 August 2013; Revised 22 September 2013; Accepted 25 September 2013

Academic Editor: Kean Aw

Copyright (C) 2013 Aiad Hassan et al. This is an open access article distributed under the Creative Commons Attribution License, which permits unrestricted use, distribution, and reproduction in any medium, provided the original work is properly cited.

\begin{abstract}
The length change is negligible and can be attributed to the normal distension of concrete. On the other hand, concrete suffering from mass loss gives a good indicator about the durability of SCC. Permeability of concrete is an important factor in classifying its durability generally; concrete with low Permeability will afford better protection of the reinforcement within it than concrete with high Permeability. In this paper, the assessment of magnesium sulphate (MS) attack on concrete containing various ratios of the supplementary cementitious materials (SCM) was investigated for concrete containing FA, RHA, and GGBS with cement replacement levels of $15 \%, 10 \%$, and $5 \%$, respectively, based on the selected samples from the concrete to the statement of the effect of magnesium on some of the characteristics of concrete such as compressive strength, height, and weight compared with similar samples but under laboratory conditions dry and moist water treatment. Test results showed that the SCC content SCM appear to have higher strength values than those stored in water and air sample; the highest value of mass loss is recorded for the control mixture compared with concrete content SCM, and the change in length in curing concrete is much less relative to the change for concrete immersed in MS
\end{abstract}

\section{Introduction}

The external attack of sulphate salts is considered as one of the major problems affecting concrete durability. Sulphates are highly soluble salts in the form of sodium sulphate $\left(\mathrm{Na}_{2} \mathrm{SO}_{4}\right)$, calcium sulphate $\left(\mathrm{CaSO}_{4}\right)$, potassium sulphate $\left(\mathrm{K}_{2} \mathrm{SO}_{4}\right)$, and magnesium sulphate $\left(\mathrm{MgSO}_{4}\right)$. Sulphate attack is a process in which sulphates react with various phases of hydrated cement paste leading to deterioration of the concrete matrix through spalling, softening, and mass loss, which may lead to expansion and loose strength and elasticity. It is recognized as a complex process due to the effect of numerous controlling factors $[1,2]$.

It has been reported that the addition of mineral admixtures to concrete would enhance its resistance to sulphate attack [2]. One of the most promising mineral admixtures is the rice husk ash (RHA), rice husk is an agricultural residue from the rice milling process. According to the FAO annual report of the United Nations [3], the annual world rice production in 2007 was estimated to be 649.7 million tons, of which the husk constitutes approximately $20 \mathrm{wt} \%$ thereof. Burning the husk at the controlled temperature below $800^{\circ}$ can produce ash with silica mainly in amorphous form [46]. Based on previous studies RHA has not been utilized yet in the construction industry with the exception of repair works at the Bowman Dam in northern California's Sierra Nevada Mountains, USA; it showed positive results in a drymix shotcrete [7]. The reason for not utilising this material is probably due to the lack of understanding of the characteristics of the RHA blended concrete. Many researchers have already published articles about the properties of the blended RHA concrete, such as strength and durability; nonetheless, the effect of RHA on concrete resistance to sulphate attack with SCC was investigated limitedly.

Fly ash is divided into two classes: Class-F and ClassC. Class-F fly ash is normally produced from the burning of anthracite or bituminous coal and has pozzolanic properties but little or no cementitious properties. Class-C fly ash is normally produced from the burning of lignite or subbituminous coal and has some autogenous cementitious 
TABLE 1: Specific gravity and water absorption of coarse and fine aggregate.

\begin{tabular}{lcccc}
\hline \multirow{2}{*}{ Aggregate } & \multicolumn{3}{c}{ Specific gravity } & \multirow{2}{*}{ Absorption (\%) } \\
& Oven-dry & SSD & Apparent & \\
\hline $\begin{array}{l}\text { Granite } \\
\text { Fine aggregate }\end{array}$ & 2.40 & 2.61 & 3.04 & 1.43 \\
(river sand) & 2.31 & 2.39 & 2.50 & 2.38 \\
\hline
\end{tabular}

TABLE 2: Chemical composition of binder materials.

\begin{tabular}{lcccc}
\hline Constituents (wt \%) & OPC & RHA & (FA) & GGBS \\
\hline $\mathrm{SiO}_{2}$ & 16.5 & 90.55 & 41.29 & 35 \\
$\mathrm{Fe}_{2} \mathrm{O}_{3}$ & 3.633 & 0.91 & 12.36 & 0.52 \\
$\mathrm{CaO}$ & 69.43 & 1.23 & 1.0 & 40 \\
$\mathrm{MgO}$ & 1.29 & 0.44 & 2.62 & 8 \\
$\mathrm{~K}_{2} \mathrm{O}$ & 0.489 & 5.52 & 2.49 & 0.46 \\
$\mathrm{SO}_{3}$ & 4.23 & 0.81 & 3.0 & 2.09 \\
$\mathrm{Al}_{2} \mathrm{O}_{3}$ & 3.65 & 0.67 & 23.59 & 11.72 \\
$\mathrm{LOI}$ & 2.14 & 2.62 & 6 & 1.42 \\
$\mathrm{Physical} \mathrm{properties}_{\quad}$ & & & & \\
Specific surface area $\left(\mathrm{m}^{2} / \mathrm{kg}\right)$ & 320 & 350 & 570 & 450 \\
Specific gravity & 3.14 & 2.15 & 2.6 & 2.1 \\
\hline
\end{tabular}

properties [8]. However, most fly ashes that are being used in concrete production are Class-F. The use of fly ash influences compressive strength, workability, heat of hydration, sulphate resistance, permeability, and the alkali-silica reaction of concrete [9].

Ground granulated blast furnace slag (GGBS) is a waste product in the manufacture of pig iron, in which about $300 \mathrm{~kg}$ of slag is produced for each tonne of pig iron [10]. When this slag is rapidly quenched and ground, it will possess latent cementitious properties. After processing, the material is known as GGBS. The hydraulic properties may vary and can be separated into grades according to ASTM C989 [11].

The objectives of this paper are to assess and find the best indicator for concrete deterioration due to accelerated sulphate attack and to investigate the effect of RHA, FA, and GGBS on concrete resistance to sulphate attack. The chemical properties of SCM and control mix using OPC were investigated. Mixture proportioning was performed to produce high workability concrete (600-700 $\mathrm{mm}$ slump flow) with target strength of $40 \mathrm{MPa}$ for the control mixture. A total of four concrete mixtures were immersed in the MS solution. The sulphate attack for the concrete specimens was assessed by the subsequent testing of the changes in the compressive strength, length, and mass.

\section{Constituent Material}

2.1. Aggregates. The maximum size of coarse aggregate used was $14 \mathrm{~mm}$. The results of the specific gravity and absorption for the normal coarse aggregate and normal sand are presented in Table 1.
2.2. Ordinary Portland Cement. Locally manufactured ordinary Portland cement conforming to MS 522: Part1: 2003 Typel was used for all mixtures.

2.3. Rice Husk Ash (RHA). The detailed chemical analysis is summarized in Table 2 for RHA. It contains $87-97 \%$ of silica with small amounts of alkali and other trace elements [12].

2.4. Fly Ash (FA). The replacement of cement by fly ash in the production of concrete is possible up to 50\% [9]. The fly ash used in this experiment meets the requirement of BS EN $450: 1995$. It was used as $15 \%$ replacement of cement, which leads to an improvement in the strength of concrete to more than $40 \mathrm{MPa}$ as shown in Table 2.

2.5. Ground Granulated Blast Furnace Slag (GGBS). Details of the chemical analysis are summarized in Table 2 for (GGBS). The fineness of GGBS is usually greater than $350 \mathrm{~m}^{2} / \mathrm{kg}$ and occasionally in excess of $500 \mathrm{~m}^{2} / \mathrm{kg}$; the specific gravity is 2.9 [11]. In this study, the GGBS fineness of $450 \mathrm{~m}^{2} / \mathrm{kg}$ was used. The raw material for GGBS, raw slag, is usually obtained from a predetermined steel plant, which ensures the stability of the raw material. The chemical composition and physical properties of the binder are illustrated in Table 2.

2.6. Superplasticizer. The superplasticizer used in this study was (SP-1600). It is an aqueous solution of modified polycarboxylate copolymers that meets the requirements of ASTM C494-86 Type G and BS 5075: Part 3. It facilitates extreme water reduction, excellent flowability with optimal cohesion, and strong self-compacting concrete. It did not contain chlorides or other ingredients that promote steel corrosion.

\section{Experimental Programme}

In this experiment, four parameters were investigated, SCC with ordinary Portland cement (OPC), fly ash (FA), rice husk ash (RHA), and ground granulated blast furnace slag (GGBS). In the SCCOPC, three mixes with different quantities of cement were used.

Three percentages were used for the experiments with FA, RHA, and GGBS. Details of the above-mentioned experimental work plan are shown in Figure 1.

3.1. Mix Design. The Japanese concept of design of SCC is based on a method proposed by Okamura and Ozawa [13]. The authors proposed a simple mix-proportioning system assuming a general supply from ready-mixed concrete plants. In this paper, the mix design proposed included the following.

(1) Coarse aggregate content which was fixed at $45 \%$ of the solid volume.

(2) Fine aggregate content which was fixed at $55 \%$ of the mortar volume. 


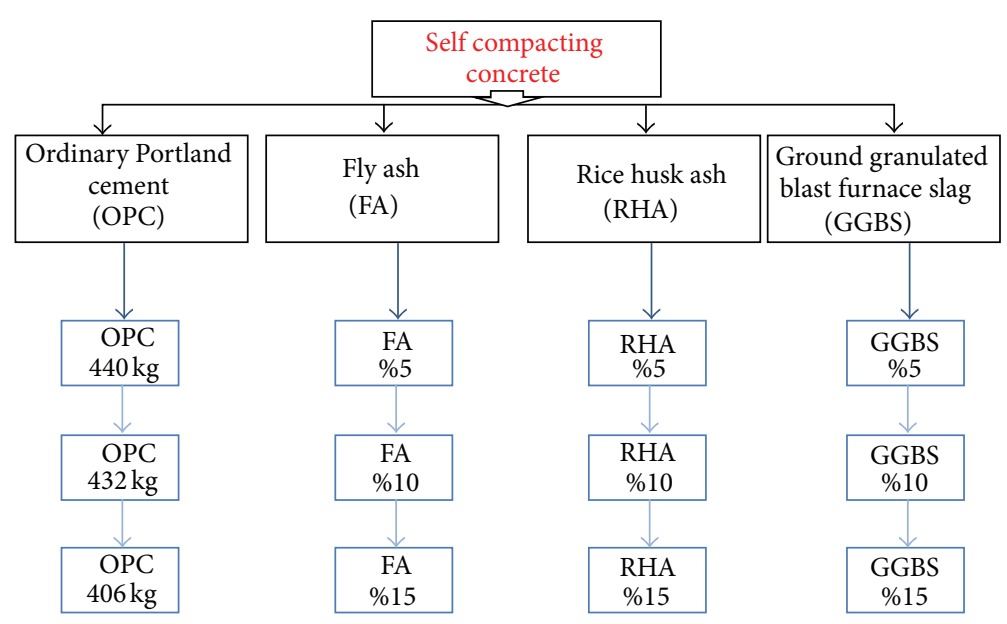

FIGURE 1: Mix proportions of various mixes.

TABLE 3: Selected mix proportion of SCC with various supplementary material ratios.

\begin{tabular}{|c|c|c|c|c|c|c|c|}
\hline Mix. No. & $\mathrm{W} / \mathrm{p} \%$ & Cement (kg) & F.A (kg) & C.A (kg) & Water $(\mathrm{kg})$ & S.P (kg) & $\begin{array}{c}\text { Pozzolanic materials } \\
\text { (FA,RHA,GGBS) }\end{array}$ \\
\hline SCCOPC & 0.53 & 406 & 895 & 732 & 215 & 2 & 0 \\
\hline SCCFA (15\%) & 0.53 & 349 & 895 & 732 & 201 & 2 & 57 \\
\hline SCCRHA (10\%) & 0.53 & 368 & 895 & 732 & 201 & 2 & 38 \\
\hline SCCGGBS (5\%) & 0.53 & 388 & 895 & 732 & 201 & 2 & 18 \\
\hline
\end{tabular}

C.A: coarse aggregate, F.A: fine aggregate, SP: superplasticizer.

(3) Water-powder ratio in volume was assumed as 1.2 to 2.0 depending on the properties of the powder and cement.

(4) Superplasticizer dosage and the final water-powder ratio were determined so as to ensure the selfcompactability.

Table 3 depicts the properties of the mix proportion and selected mix proportion of SCC for the final mix.

\section{Methodology}

A magnesium sulphate hydrate dissolved in water with a content of $5 \mathrm{wt} \%$ was used in the study as a salt. All the specimens that were subjected to sulphate attack were initially cured in water for 7 days after remoulding. They were then immersed in the magnesium sulphate solution. The sulphate treatment was done in three cycles; each cycle consisted of 30 days of sulphate immersion followed by 7 days of air drying and tests were conducted at the end of each cycle. The sulphate solution was replaced every 15 days in each cycle.

The length and mass changes were monitored on three concrete cube specimens of $100 \times 100 \times 100 \mathrm{~mm}$. For length change measurements, four readings were taken from each specimen at the end of each immersion cycle. The average length was then recorded and the results were expressed as a percentage with respect to the length changes, with the other samples left in the curing tank at the same age and during the drying age.

\section{Fresh Concrete Properties}

The fresh properties are given in Table 4 for all concrete mixtures incorporating RHA, FA, and GGBS; no bleeding or segregation was detected. The fresh density was in the range of $2280-2440 \mathrm{~kg} / \mathrm{m}^{3}$, which characterizes all the relevant workability aspects and hence each mix was tested with different method for the different workability parameters. The slump flow test was used to assess the horizontal free flow of SCC in the absence of obstructions. Time $T_{50 \mathrm{~cm}}$ is the secondary indicator of the flow funnel; it indicates the tendency for segregation, wherein the funnel can be refilled with concrete and left for 5 minutes to settle. The L-box test was used to determine the passing ability. The results could be estimated according to the limits of the standard for SCC concrete.

\section{Results and Discussion}

6.1. Comparing the Effect of MS with Curing Condition on SCC. The results illustrated in Table 5 and Figure 2 explain the compressive strength between the concrete immersed in MS and the standard curing of the concrete. The figures show the improvement of the strength immersed in MS relative to the strength of curing with water on all concrete mixed with the SCM products, such as FA, RHA, and GGBS. This can be attributed to the formation of the expansive ettringite in the presence of tricalcium aluminate inside the cement paste 
TABLE 4: Results of workability fresh SCC containing SCM.

\begin{tabular}{|c|c|c|c|c|c|c|}
\hline Mix.no. & V-funnel (sec) & $\mathrm{T}_{50}(\mathrm{sec})$ & Slump flow (mm) & L-BOX \% & Segregation \% & J-ring $(\mathrm{mm})$ \\
\hline SCCOPC & 5 & 4 & 610 & 85 & $4 \%$ & 10 \\
\hline SCCFA15 & 7 & 5 & 610 & 89 & $6 \%$ & 10 \\
\hline SCCRHA10 & 9 & 5 & 630 & 81 & $7 \%$ & 13 \\
\hline SCCGGBS5 & 8 & 6 & 650 & 82 & $15 \%$ & 15 \\
\hline
\end{tabular}

TABLE 5: Effect of MS on the strength with curing SCC.

Compressive strength/MPa

\begin{tabular}{lccccccccc} 
Mix. no. & \multicolumn{3}{c}{ Magnesium sulphate (a) } & \multicolumn{3}{c}{ Water curing (b) } & \multicolumn{3}{c}{ Relative strength \% (a/b) } \\
& $44 \mathrm{~d}$ & $81 \mathrm{~d}$ & $118 \mathrm{~d}$ & $44 \mathrm{~d}$ & $81 \mathrm{~d}$ & $118 \mathrm{~d}$ & $44 \mathrm{~d}$ & $81 \mathrm{~d}$ & $118 \mathrm{~d}$ \\
\hline SCCOPC & 42 & 44 & 48 & 40 & 42 & 46 & 1.05 & 1.05 \\
SCCFA15 & 52 & 53 & 54 & 50 & 52 & 53 & 1.04 & 1.02 & 1.04 \\
SCCRHA10 & 51 & 53 & 56 & 41 & 43 & 46 & 1.24 & 1.23 \\
SCCGGBS5 & 52 & 53 & 54 & 47 & 48 & 49 & 1.11 & 1.10 \\
\hline
\end{tabular}

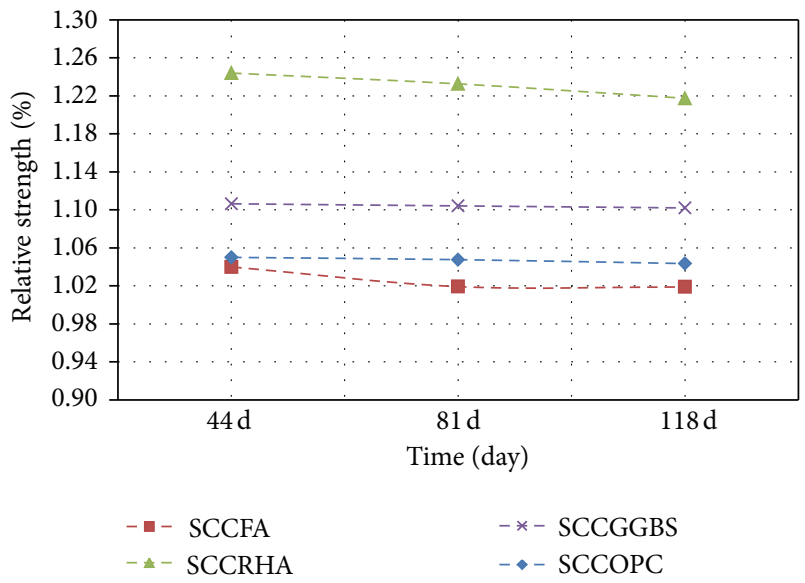

FIGURE 2: Effect of MS on the strength with curing water SCC.

matrix and the infiltrated $\mathrm{SO}_{4}{ }^{+}$ion, which resulted in filling the voids, thus increasing the concrete maturity [14].

In this study, it can also be observed from the compressive strength results that all concrete specimens immersed in MS up to the third cycle (111d of sulphate exposure) containing FA exhibited higher values than others types of concrete containing RHA and GGBS because the $\mathrm{SO}_{4}{ }^{+}$ion contents in FA are higher than for the RHA and GGBS, which causes the voids to be filled look better and the strength to develop quicker, as explained in Table 2.

\subsection{Comparison between Magnesium Sulphate and Air Drying} Strength SCC. For the values of the compressive strength for the hardened concrete mixtures immersed in sulphate, "the control drying specimens" along with the relative compressive strength when tested at the same age are shown in Table 6. It can be observed that the relative strength of the concrete immersed in sulphate compared to those air dried increased with concrete containing SCM, such as FA, RHA, and GGBS in less time. For example, the relative strength for the 15 FA mixtures was $16 \%$ at the first cycle (37 days of sulphate exposure). However, in the third cycle (111 days), the

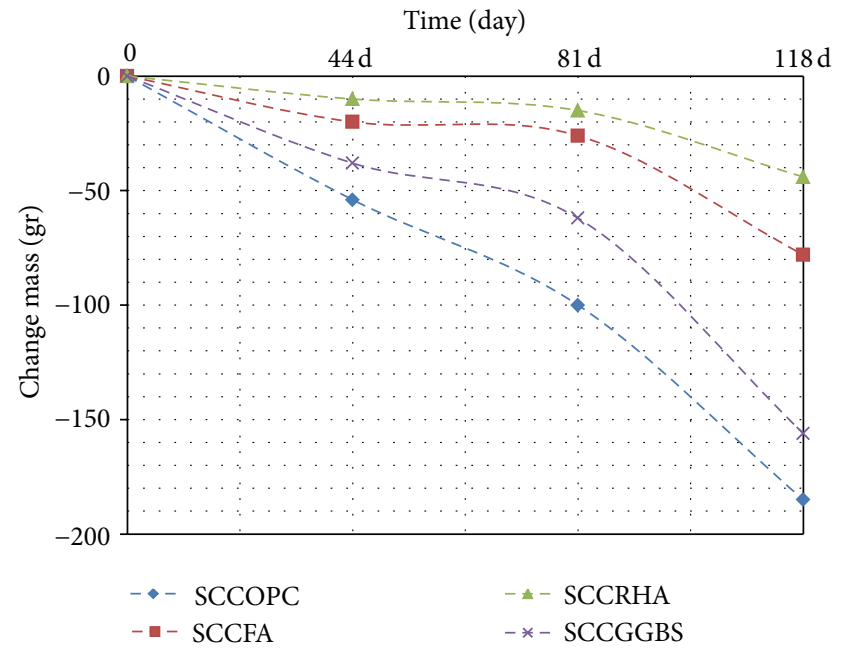

FIGURE 3: Effect of change in mass between MS and water curing.

value was reduced to $8 \%$. In addition, the value of the relative strength also decreased for 10 RHA and 5 GGBS. Because increase the binder material and need to be treated with water causing incomplete interaction between the components of the concrete, causing shrinkage of concrete and thus affected to the durability of concrete [15].

The effect of the MS attack on the cement paste showed that specimens immersed in the $\mathrm{MgSO}_{4}$ solution at room temperature exhibited a higher compressive strength than specimen's air dried for up to 120 days. At later ages, the adverse effect of sulphate on strength was dominant [15].

6.3. Effect of Magnesium Sulphate on Change in Mass. The change in mass for the concrete exposures to sulphate up to 118 days compared with the mass stored in water and drying specimens in the laboratory taken at the same ages is given in Figures 3 and 7. The results show that the highest value of mass loss is recorded for the control mixture, which has a loss of mass at the curing case in the third cycle of display. In as much as the loss of mass for the 10 RHA, 15 FA and 
TABLE 6: Effect of MS on the strength with air drying SCC.

Compressive strength $(\mathrm{MPa})$

\begin{tabular}{|c|c|c|c|c|c|c|c|c|c|}
\hline \multirow[t]{2}{*}{ Mix. no. } & \multicolumn{3}{|c|}{ Sulphate solution } & \multicolumn{3}{|c|}{ Air dried } & \multicolumn{3}{|c|}{ Relative strength \% } \\
\hline & $44 \mathrm{~d}$ & $81 \mathrm{~d}$ & $118 \mathrm{~d}$ & $44 \mathrm{~d}$ & $81 \mathrm{~d}$ & $118 \mathrm{~d}$ & $44 \mathrm{~d}$ & $81 \mathrm{~d}$ & $118 \mathrm{~d}$ \\
\hline SCCOPC & 42 & 44 & 48 & 39 & 41 & 44 & 1.08 & 1.07 & 1.09 \\
\hline SCCFA15 & 52 & 53 & 54 & 45 & 46 & 50 & 1.16 & 1.15 & 1.08 \\
\hline SCCRHA10 & 51 & 53 & 56 & 44 & 45 & 49 & 1.16 & 1.18 & 1.14 \\
\hline SCCGGBS5 & 52 & 53 & 54 & 43 & 45 & 47 & 1.21 & 1.18 & 1.15 \\
\hline
\end{tabular}

TABLE 7: Effect of MS on the mass with air drying SCC.

\begin{tabular}{|c|c|c|c|c|c|c|c|c|c|}
\hline \multirow{3}{*}{ Mix. no. } & \multicolumn{9}{|c|}{ Mass (gr) } \\
\hline & \multicolumn{3}{|c|}{ Magnesium sulphate } & \multicolumn{3}{|c|}{ Air dried } & \multicolumn{3}{|c|}{ Curing water } \\
\hline & $44 \mathrm{~d}$ & $81 \mathrm{~d}$ & $118 \mathrm{~d}$ & $44 \mathrm{~d}$ & $81 \mathrm{~d}$ & $118 \mathrm{~d}$ & $44 \mathrm{~d}$ & $81 \mathrm{~d}$ & $118 \mathrm{~d}$ \\
\hline SCCOPC & 2220 & 2240 & 2240 & 2222 & 2206 & 2202 & 2274 & 2340 & 2425 \\
\hline SCCFA15 & 2460 & 2414 & 2402 & 2334 & 2332 & 2320 & 2480 & 2440 & 2480 \\
\hline SCCRHA10 & 2365 & 2353 & 2342 & 2272 & 2265 & 2200 & 2375 & 2368 & 2386 \\
\hline SCCGGBS5 & 2332 & 2320 & 2242 & 2246 & 2266 & 2280 & 2370 & 2382 & 2398 \\
\hline
\end{tabular}

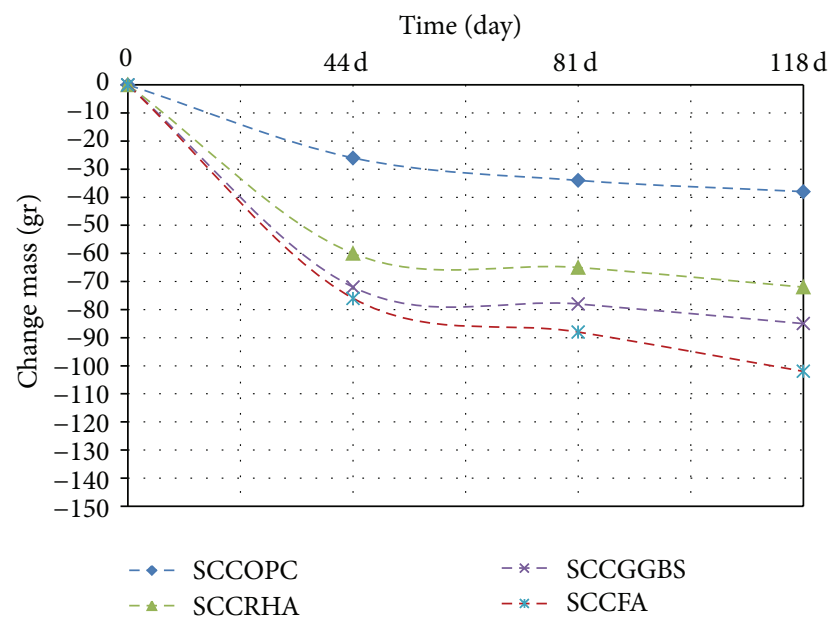

FIGURE 4: Effect on MS with air dried at SCC containing SCM.

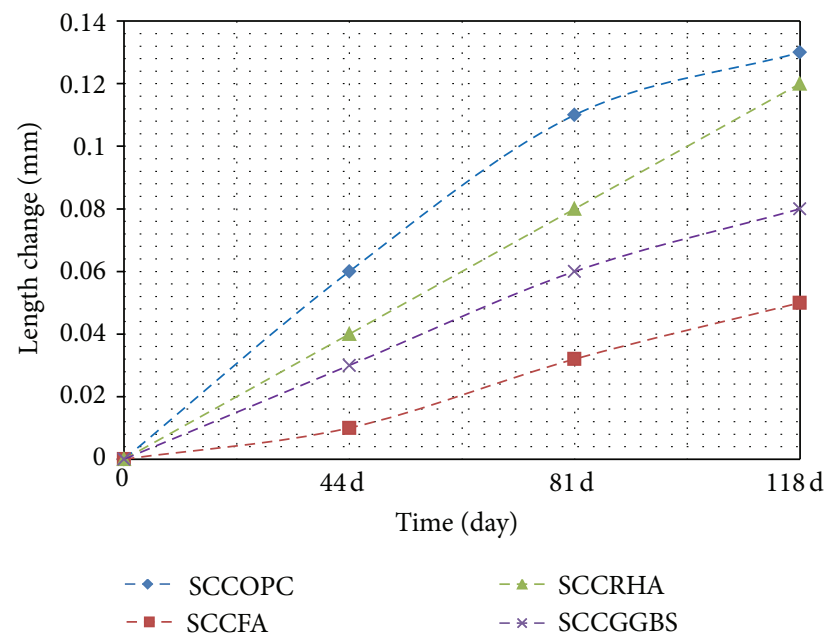

FIGURE 5: Length affected by the addition of MS and curing ages at SCC.

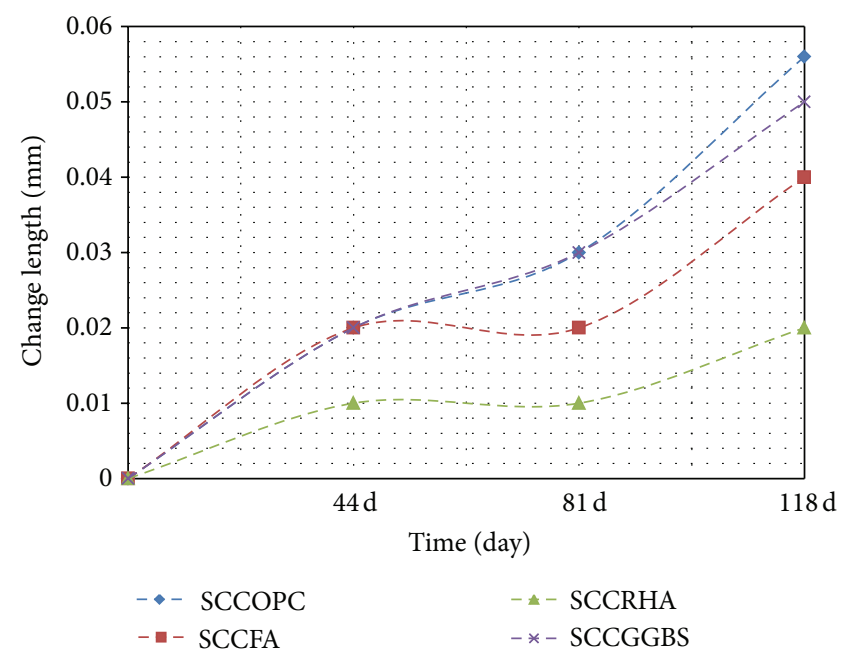

FIGURE 6: Length affected by MS and air dried in SCC.

5GGBS were less than the control mix; the RHA blended cement concrete results in better resistance to sulphate attack; therefore, the mass loss can be a measure of sulphate attack due to the gypsum formation. Polviska postulated/reported that the loss of mass is the best indicator to assess the degree of deterioration compared to changes in length and strength [16].

In the drying test, for all mixes the reduction in weight can be attributed to the formation of gypsum on the concrete surface which also results in the softening and spalling of the concrete surface. In addition, the presence of SCM leads to more shrinkage in FA, GGBS, and RHA, respectively compared with control mix. The reason it surface area of these materials and thus leads to reduce the weight (see Figure 4, Table 7).

The drying shrinkage tends to decrease in SCC since a very small amount of free water is available in the system. 
TABLE 8: Length affected by the addition of MS and curing ages at SCC.

\begin{tabular}{|c|c|c|c|c|c|c|c|c|c|}
\hline \multirow{3}{*}{ Mix. no. } & \multicolumn{9}{|c|}{ Length at $(\mathrm{mm})$} \\
\hline & \multicolumn{3}{|c|}{ Magnesium sulphate } & \multicolumn{3}{|c|}{ Curing age } & \multicolumn{3}{|c|}{ Air dried } \\
\hline & $44 \mathrm{~d}$ & $81 \mathrm{~d}$ & $118 \mathrm{~d}$ & $44 \mathrm{~d}$ & $81 \mathrm{~d}$ & $118 \mathrm{~d}$ & $44 \mathrm{~d}$ & $81 \mathrm{~d}$ & $118 \mathrm{~d}$ \\
\hline SCCOPC & 100.400 & 100.37 & 100.36 & 100.46 & 100.48 & 100.49 & 100.40 & 100.40 & 100.39 \\
\hline SCCFA & 100.36 & 100.36 & 100.34 & 100.37 & 100.39 & 100.39 & 100.38 & 100.38 & 100.38 \\
\hline SCCRHA & 100.38 & 100.34 & 100.34 & 100.42 & 100.42 & 100.46 & 100.4 & 100.37 & 100.39 \\
\hline SCCGGBS & 100.39 & 100.39 & 100.34 & 100.42 & 100.45 & 100.42 & 100.40 & 100.40 & 100.39 \\
\hline
\end{tabular}

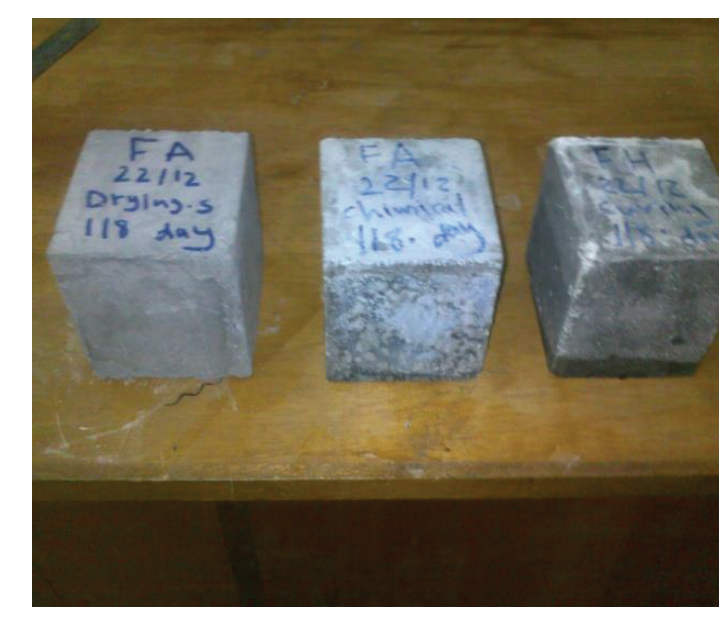

(a) SCCFA

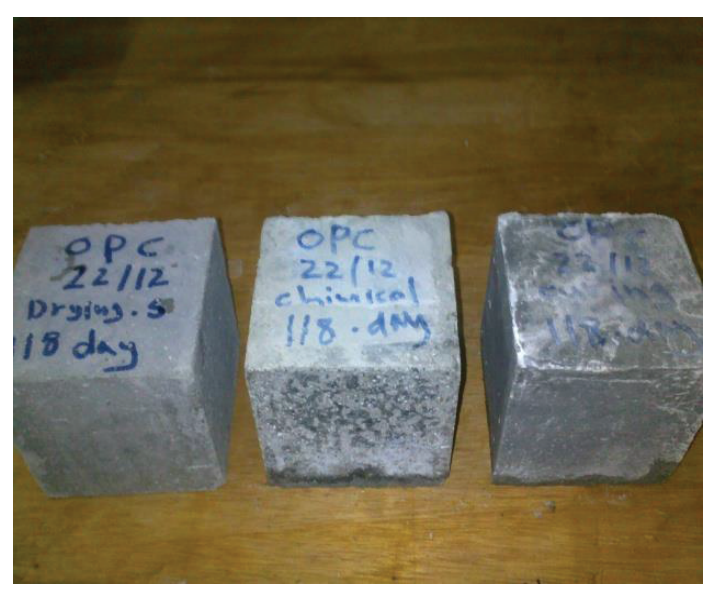

(c) SCCOPC

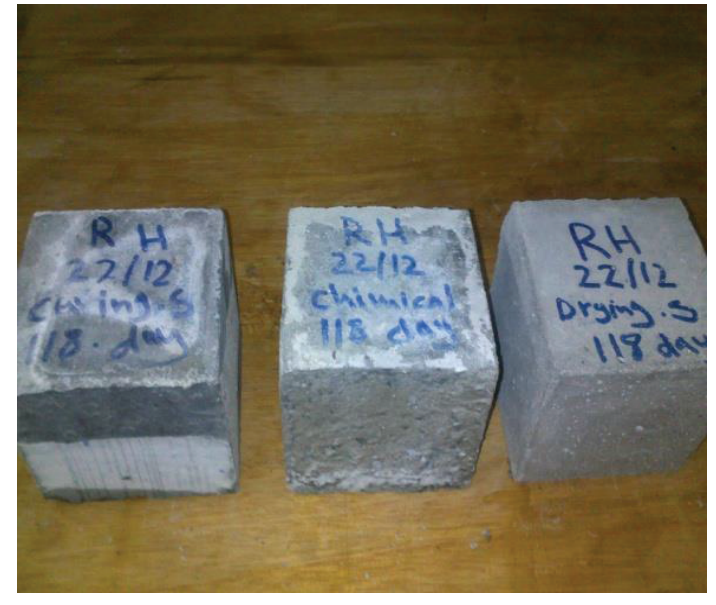

(b) SCCRHA

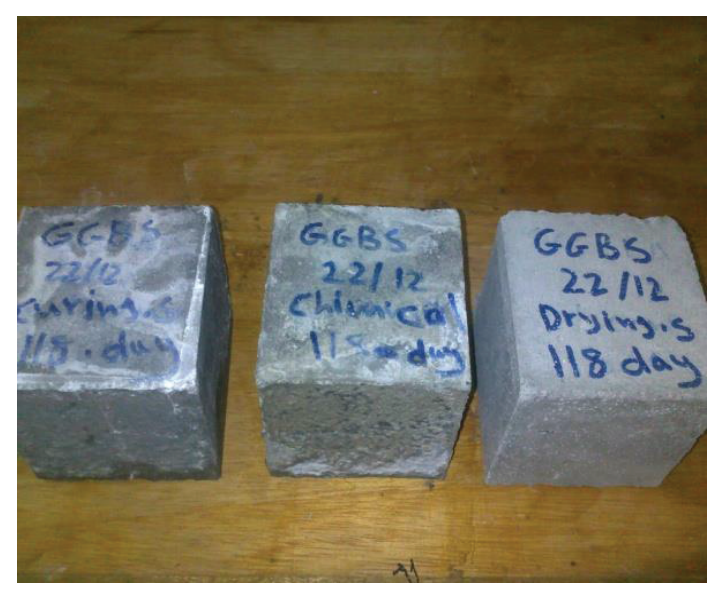

(d) SCCGGBS

FIGURE 7: Optical observation of the concrete exposed to MS, water and the drying age of SCC containing various SCM.

Also, SCC has minimum empty voids on the concrete surface that are largely responsible for drying shrinkage [17].

6.4. Effect of Magnesium Sulphate on Length Change at SCC. The percentage of expansion for the concrete exposed to sulphate for up to 118 days compared with the length at curing and drying for the same ages is given in Figures 5 and 6, respectively. It can be observed that the values of expansion are low and comparable with the concrete immersed in magnesium sulphate. Thus, concrete expansion may be attributed to the normal swelling of concrete. Kalousek and Benton [18] proved experimentally that no correlation exists between the amount of ettringite precipitated and expansion, and it may be assumed that ettringite deposits in voids, and, therefore, exerts very little or no expansion.

The results illustrated in Table 8 and Figure 5 show the change in the length between the concrete immersed in magnesium sulphate and concrete stored in water. It is observable that the change in length in this case is much less relative to the change for concrete immersed in magnesium sulphate. The experimental consequences revealed that the concrete containing SCM grade 40 exhibits less swelling in the volume of the concrete sample. The reason for the FA, 
RHA, and GGBS mixes is because it closes the voids to look better than the control mix OPC. This is due to the variation in the degree of fineness, which causes the expansion to exhibit different behaviour as the swelling of the concrete is dependent on the particle size and fineness degree of SCM. It is generally agreed that shrinkage increases with the increase in the cement content because this results in a large volume of hydrated cement paste, which is liable to shrink [10]. In addition, the changes in the length of concrete through air drying compared with the concrete immersed in magnesium sulphate exhibited the same behaviour, as shown in Figure 6.

\subsection{Identify Concrete Deterioration due to Sulphate Attack.} Throughout this study, it was possible to evaluate the effect of sulphate attack on concrete mixes by testing the changes in strength, height, and mass, in addition to observing the optical appearance of the test samples, as shown in Figure 7. It is acknowledged that the best indicator to evaluate the degradation of concrete is to measure the mass change and monitor the visual appearance of the test samples. The RHA, FA, and GGBS mixtures show the pozzolanic reaction which continues to increase and reduce the infiltration of $\mathrm{SO}_{4}{ }^{+}$ions within the concrete. A major impact to improve the durability properties of concrete effect in sulphate magnesium, and shows more accurate in all the mixes by using SCM.

\section{Conclusion}

The following conclusions can be drawn based on the results of the current study.

(1) For the third cycle of exposure to sulphate attack, the concrete SCC contents 15FA, 10RHA, and 5GGBS appear to have higher strength values than those stored in water and air sample.

(2) The highest value of mass loss is recorded for the control mixture, which has reduced the mass at the curing case at third cycle of exposures. In the drying test, the mass loss for all mixes is attributed to the formation of gypsum on the concrete surface in addition to the presence of SCM, which leads to more shrinkage and, consequently, a decrease in mass.

(3) The change in length in curing concrete is much less relative to the change for concrete immersed in MS. In addition, the change in the length of concrete through air drying compared with the concrete immersed in MS exhibited the same behaviour because the values of expansion are low and comparable. Thus, concrete containing SCM, such as FA, RHA, and GGBS, exhibited expansion, which may be attributed to the normal swelling of concrete with consequent increase in length.

(4) Generally, adding FA, RHA, and GGBS to SCC improves its resistance to sulphate attack. Increasing the SCM fineness will enhance its resistance, which is due to the increased pozzolanic activity.

\section{Acknowledgments}

The authors wish to acknowledge the support provided by the Science Fund (13-02-03-3092) entitled "Exploring the Potential of Malaysian Palm Oil Fuel Ash in Developing Durable Self-Compacting Concrete" and also the support from the University of Malaya.

\section{References}

[1] M. H. Shehata, G. Adhikari, and S. Radomski, "Long-term durability of blended cement against sulfate attack," ACI Materials Journal, vol. 105, no. 6, pp. 594-602, 2008.

[2] T. H. Wee, A. K. Suryavanshi, S. F. Wong, and A. K. M. Anisur Rahman, "Sulfate resistance of concrete containing mineral admixtures," ACI Structural Journal, vol. 97, no. 5, pp. 536-549, 2000.

[3] FAO, World Paddy Production for, Food and Agriculture Organization of the United Nations, 2008.

[4] S. Chandrasekhar, K. G. Satyanarayana, P. N. Pramada, P. Raghavan, and T. N. Gupta, "Processing, properties and applications of reactive silica from rice husk-an overview," Journal of Materials Science, vol. 38, no. 15, pp. 3159-3168, 2003.

[5] D. V. Reddy and B. S. Marcelina, "Marine durability characteristics of rice husk ash-modified reinforced concrete," in Proceedings of the 4th LACCET International Latin American and Caribbean Conference for Engineering and Technology, p. 134, San Juan, Puerto Rico, USA, 2006.

[6] M.-H. Zhang and V. M. Malhotra, "High-performance concrete incorporating rice husk ash as a supplementary cementing material," ACI Materials Journal, vol. 93, no. 6, pp. 629-636, 1996.

[7] D. Talend, The Best-Kept Secret to High-Performance Concrete, The Aberdeen Group, Boston, Mass, USA, 1997.

[8] H. Y. Wang and K. C. Tsai, "Engineering properties of lightweight aggregate concrete made from dredged silt," Cement and Concrete Composites, vol. 28, no. 5, pp. 481-485, 2006.

[9] W. E. Ellis Jr., "For durable concrete, fly ash does not "replace" cement," Concrete International, vol. 14, no. 7, pp. 47-51, 1992.

[10] A. M. Neville, Properties of Concrete, England Longman, 4th edition, 1995.

[11] ASTM, Specification for Ground Granulated Plats-Furnace Slag for Use in Concrete and Mortars, Book of ASTM Standards: Concrete and Aggregates, American Society for Testing and Materials, Philadelphia, Pa, USA, 2006.

[12] C. S. Prasad, K. N. Maiti, and R. Venugopal, "Effect of substitution of quartz by rice husk ash and silica fume on the properties of whiteware compositions," Ceramics International, vol. 29, no. 8, pp. 907-914, 2003.

[13] H. Okamura and K. Ozawa ', "Mix design for self-compacting concrete," Concrete Library of JSCE, no. 25, pp. 107-120, 1995.

[14] G. A. Habeeb, H. B. Mahmud, and N. B. A. A. Hamid, "Assessment of deterioration in RHA-concrete due to magnesium sulphate attack," International Journal of Minerals, Metallurgy and Materials, vol. 17, no. 6, pp. 691-696, 2010.

[15] E. E. Hekal, E. Kishar, and H. Mostafa, "Magnesium sulfate attack on hardened blended cement pastes under different circumstances," Cement and Concrete Research, vol. 32, no. 9, pp. 1421-1427, 2002.

[16] M. Polivka and E. H. Brown, "Influence of various factors onsulfate resistance of concrete containing pozzolans," ProceedingsAmerican Society for Testing Materials, vol. 58, 1995. 
[17] D. Cusson and T. Hoogeveen, "Internal curing of high-performance concrete with pre-soaked fine lightweight aggregate for prevention of autogenous shrinkage cracking," Cement and Concrete Research, vol. 38, no. 6, pp. 757-765, 2008.

[18] G. L. Kalousek and E. J. Benton, "Mechanism of seawater attack non cement paste," Journal of American Concrete Institute, vol. 67, no. 2, pp. 187-192, 1970. 

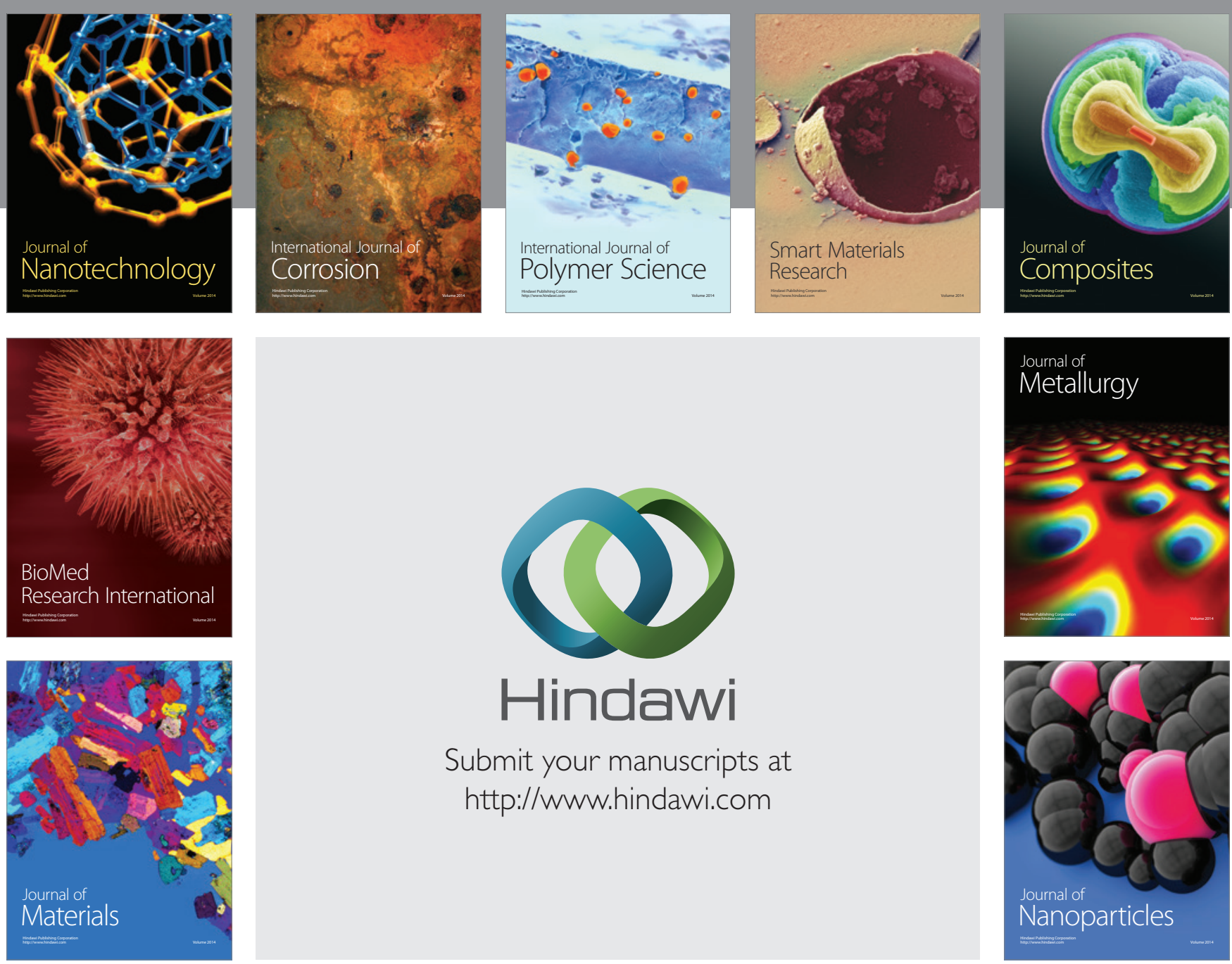

Submit your manuscripts at http://www.hindawi.com
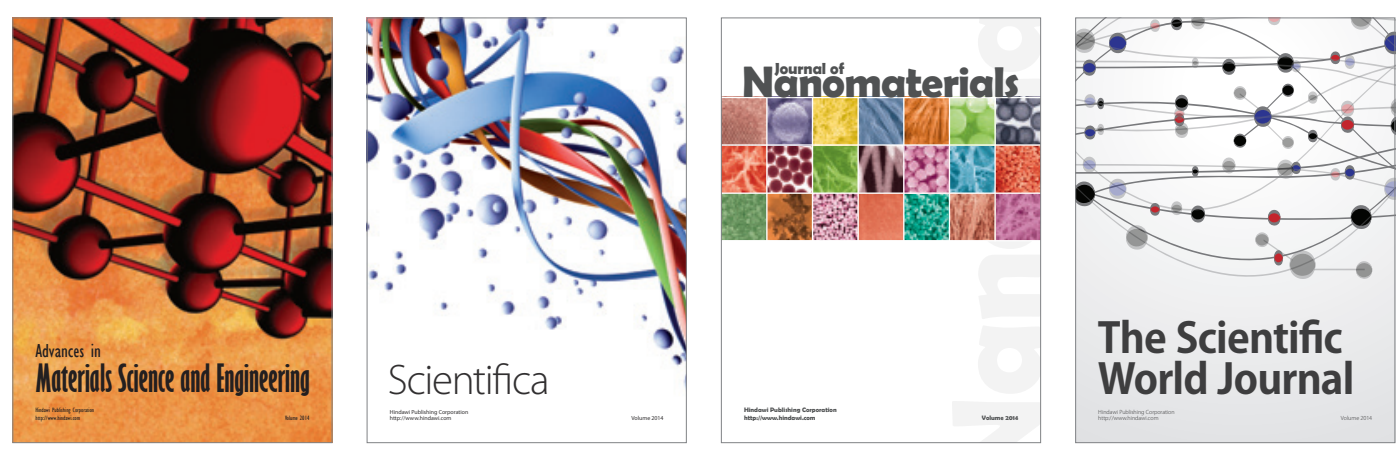

\section{The Scientific World Journal}
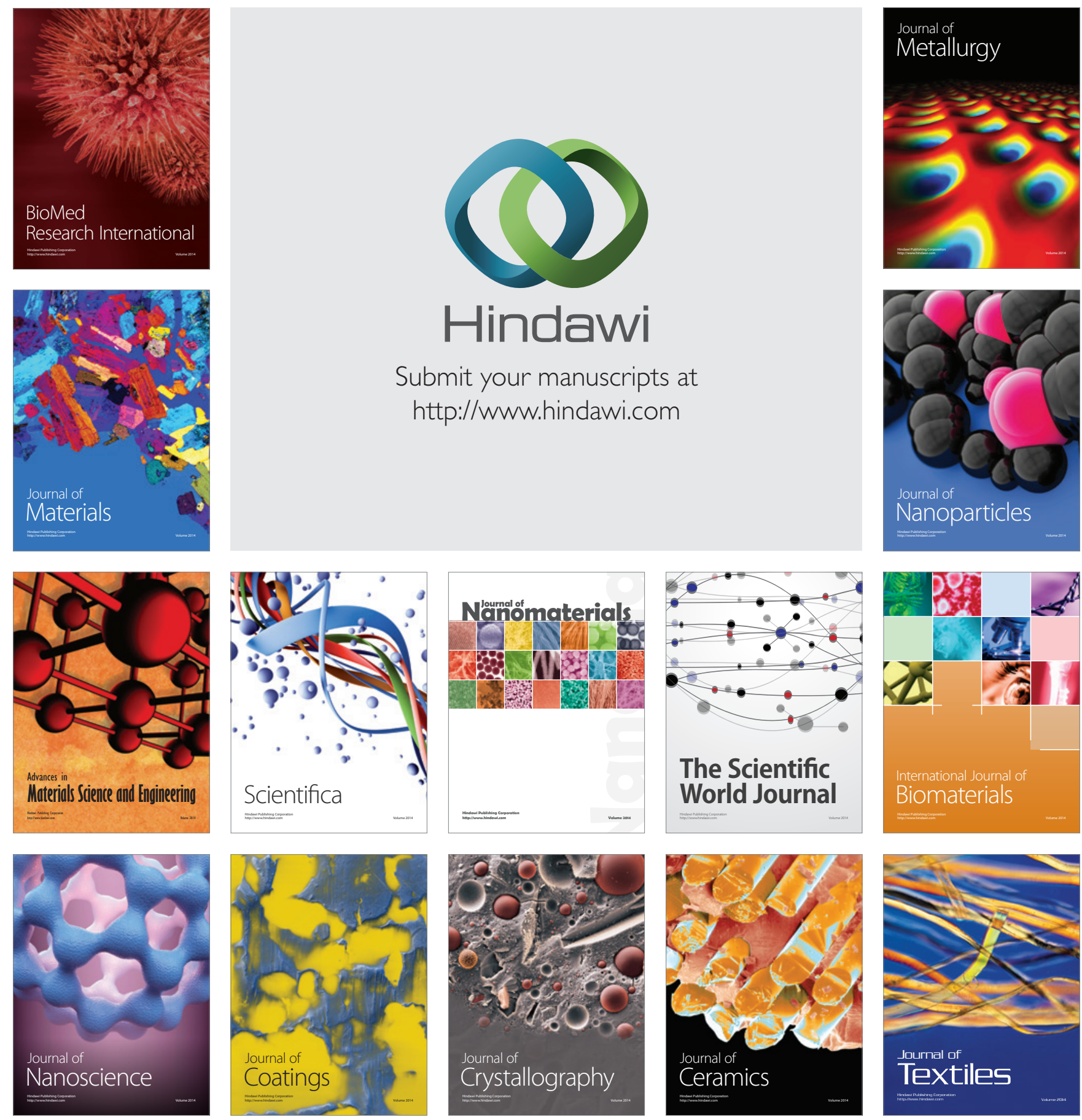